\title{
Antifungal potential of different parts of Olea europaea and Olea cuspidata growing in Azad Jammu and Kashmir
}

\author{
Muhammad Altaf Hussain ${ }^{1 *}$, Muhammad Qayyum $\mathrm{Khan}^{2}$, Imran $\mathrm{Ali}^{1}$, \\ M. Ejaz Ul Islam Dar ${ }^{2}$ and Tariq $\mathrm{Habib}^{2}$
}

\author{
${ }^{1}$ Department of Biotechnology, Mirpur University of Science and Technology (MUST), Mirpur, Azad Kashmir, \\ Pakistan \\ ${ }^{2}$ Department of Botany, University of Azad Jammu and Kashmir Muzaffarabad-13100, Pakistan \\ *Corresponding author email: altaf.bot@ must.edu.pk
}

\section{Citation}

Muhammad Altaf Hussain, Muhammad Qayyum Khan, Imran Ali, M. Ejaz Ul Islam Dar and Tariq Habib. Antifungal potential of different parts of Olea europaea and Olea cuspidata growing in Azad Jammu and Kashmir. Pure and Applied Biology. Vol. 4, Issue 2, 2015, pp 204216

Received: $17 / 03 / 2015$

Revised: 09/05/2015

Accepted: 14/05/2015

\section{Abstract}

Development of more effective and less toxic antifungal agents is required for the treatment of fungal diseases of plants and human being. The medicinal plants and their various extracts have been used as medicines against infectious diseases and found as potent against crops as well as human pathogenic fungal stains. In this study, the antifungal activity of $O$. europaea (cultivated olive) leaves, seeds and $O$. cuspidata (wild olive) leaves, roots bark, stem bark and seeds were evaluated against a range of human and crop pathogenic fungal species by using well diffusion assay. The extracts of investigated parts of $O$. europaea and $O$. cuspidata obtained with organic solvents were found to be effective against some of tested fungal strains particularly extracts of $O$. cuspidata parts proved to be more potent. The ethylacetate extracts of $O$. cuspidata leaves and seeds were found to be effective against fungal pathogens as compared to $O$. europaea extracts. Nystatin was also used as positive control and respective solvent as negative control. This study demonstrated that the use of wild olive leaves extracts as medicines may reduce the risk of fungal infections, particularly in situations where lengthy usage of synthetic fungicidal inspire growth of opportunistic contagions.

Keyword: Fungicidal; Wild Olive; Cultivated Olive; Organic Solvents; HPLC 


\section{Introduction}

Extracts of olive leaves has been used in traditional medicine for the treatment of malaria and fever [1]. In animals the olive leaf extracts found to be useful particularly in lowering the blood pressure [2] and increases blood flow in coronary arteries, relieves arrhythmia and prevents intestinal muscle spasms [3]. Furthermore, olive leaf extract and its phenolic compounds such as oleuropein, tyrosol, hydroxytyrosol, caffeic acid, gallic acid and luteolin have antimicrobial activity against viruses, retroviruses, bacteria, yeasts, fungi, molds and other parasites [4-6]. The growth of Escherichia coli, Klebsiella pneumonia and Staphylococcus aureus was inhibited by the phenolic compounds isolated from olive fruit [7, 8]. Gourama and Bullerman [9] evaluated the oleuropein Aspergillus parasiticus's aflatoxin and found that oleuropein used mold growth but inhibited the production of aflatoxins. Markin et al. [10] also evaluated the antimicrobial potential of olive leaf water extract and found potent against tested yeast and bacterial strains. Moreover, Sousa et al. [11] screen out phenolic compound against a rang of G+ve, G-ve and fungi (Candida albicans and Cryptococcus neoformans) and conferred a prominent activity. The fungi i.e. Tricophyton mentagrophytes, Microsporum canis and Candida spp. were sensitive from some aldehydes isolated from fruit of olive as conferred good antifungal activity [12]. Many of the problems caused by yeasts results from the much higher attention paid to bacteria and moulds which are more significant in terms of public health. Yeasts play a central role in the spoilage of foods and beverages, mainly those with high acidity and reduced water activity [13]. Ismail et al. [14] reported that Kloeckera apiculata, Saccharomyces cerevisiae, Schizosaccharomyces pombe and Candida spp. are responsible for the spoilage of foods that have been processed and packaged according to the normal standards of good manufacturing practice. In addition, yeasts are used during biological control following harvest (Candida oleophila, Metschnikowia fructicola, etc.).

The objectives of this study were to investigate antifungal activity of organic solvents extracts from wild and cultivated olive parts which has been utilized as traditional folk medicine and to evaluate the potential usage of olive parts extracts as natural preservative.

\section{Materials and Methods}

The seeds, leaves, stem and roots bark of wild (Olea cuspidata Wall. Cat.) while seeds and leaves of cultivated (Olea europaea L) were collected from Kotli, Azad Jammu and Kashmir. All parts of wild and cultivated olive were dried carefully under shade then homogenized to powdered material and stored at $4{ }^{\circ} \mathrm{C}$ for further analysis.

\section{Fungal strains Used}

The fungal strains i.e. Aspergillus flavus, Alternaria alternata, Fusarium moniliform, Mauginiella scaettae, Trichothecium roseum, Magnaporthe grisea, Botrytis cinerea and yeast i.e. saccharomyces cerevisiae were used in the present study.

\section{Extraction of Potential Bioactive Compounds}

Extraction is very important first step in the investigation of medicinal plants because it is necessary to extract the desired chemical components from the plant materials for further separation and characterization. Keeping in view the crucial nature of chemical compound extraction procedure, for the present study the homogenized plant parts, already stored at $4{ }^{\circ} \mathrm{C}$ were weighed and laid into separate flasks. The 250 grams of each crushed plant portion was macerated separately in $400 \mathrm{ml}$ ethylacetate, acetone, chloroform and methanol for ten days at room temperature $\left(25 \pm 2{ }^{\circ} \mathrm{C}\right)$. The solvent extracted material was filtered by using 
whatmman filter paper in separate sanitized flasks. These extracts of plants portions were dried on rotary evaporator at low temperature $\left(60{ }^{\circ} \mathrm{C}\right)$ and reduced pressure [15].

\section{Culture Medium}

For fungal growth PDA (Potato dextrose agar) was used as culture medium. The PDA was mixed and dissolved in distilled water. The solution was sterilized in an autoclave at $121{ }^{\circ} \mathrm{C}$ (with $15 \mathrm{lb} / \mathrm{sq}$-inch pressure) for 15 minutes. The $\mathrm{pH}$ of the medium was maintained at 5.4.

\section{Determination of Antifungal Activities}

In past research on antifungal activity of medicinal plants has been encountering several problems because of the diversity of the criteria and techniques employed for testing. The lipophilic properties of some extracts such as oil make it very difficult to use an aqueous media in the study of antimicrobial activity. Furthermore, different microorganisms have varying degree of sensitivity to different antimicrobial agents [16]. Among the several methods which were employed in the plant research to determine their antimicrobial activities, invitro antifungal activities were assessed by using the well diffusion method [17].

\section{Preparation of Inoculum}

Fungal cultures which were 72 hours old, used as inoculums for test. The slants of PDA were prepared to maintain the fungal culture by following agar slant culture technique [18]. The slants of PDA (potato dextrose agar) were prepared in test tubes and were streaked with fungus. Each test tube was labeled with the name of fungus present in it and incubated for 72 hours at $25^{\circ} \mathrm{C}$.

\section{Preparation of Extract Dilution and Suspension}

The dried ethyl acetate, acetone, chloroform and methanol extracts were then dissolved in their respective solvents. Test tubes were sterilized in an autoclave at $121^{\circ} \mathrm{C}$ for 15 minutes. $10 \mathrm{ml}$ of distilled water was taken in each test tube. Then a loop of yeast or fungus was inoculated in distilled water in test tube under aseptic condition.

\section{Preparation of Plates}

The petri dishes were sterilized in an oven at $200{ }^{\circ} \mathrm{C}$ for 2 hours. The sterilized petri dishes were also labeled with the yeast and fungal names. The petri dishes were labeled for leaves, seeds, stem bark, roots bark and solvent used. $1 \mathrm{ml}$ of inoculum was transferred from the test tube into corresponding previously labeled petri dishes, with the help of micropipette. The sterilized potato dextrose agar medium was poured in the petri plates containing fungal suspension then allowed to solidify at room temperature.

\section{Antifungal Assay by Well Diffusion Method}

The ethyl acetate, acetone, chloroform and methanol extracts of $O$. cuspidata leaves, seeds, stem bark, roots bark while $O$. europaea leaves and seeds were assessed for antifungal activity by using agar well diffusion method [17]. The well was made with sterile cork borer of $6.0 \mathrm{~mm}$ diameter. The 72 hours old cultures of fungi, grown on potato dextrose agar (PDA) medium were used as inoculum. $1 \mathrm{ml}$ of dilution of each fungal strain was transferred into labeled petri plate and then molten PDA was poured in it by pour plate procedure. After solidification of medium, the appropriate wells were made then $10 \mu \mathrm{l}$ of crude extract laid into these labeled wells. Eight different solid-phase fractions, 100 percent $\mathrm{H}_{2} \mathrm{O}$ and 5, $10,15,20,30,40$ and 100 percent methanol were also tested in same way that were fractionated form original methanol extracts of leaves by using solid phase extraction procedure. The same volume $(10 \mu \mathrm{l})$ of nystatin with concentration $100 \mathrm{mg} / \mathrm{ml}$ was used as positive control and respective solvent as negative control. The preparative 
HPLC fraction of 100 percent $\mathrm{H}_{2} \mathrm{O}, 5$ and 100 percent methanol were also used to evaluate the antifungal potential of each fraction. All the experiments were carried out in triplicates. All these plates were incubated at $25{ }^{\circ} \mathrm{C}$ for 72 hours. After the incubation period, all the plates were examined for the presence of zones of inhibition as a possession of antifungal activity. The zone of inhibition was taken by measuring the diameter of the zone in millimeters $(\mathrm{mm})$ and was tabulated in tables.

\section{Statistical Analysis}

All values were expressed as means \pm standard error of means (S.E.M). The data for each microorganism were analyzed by using one way analysis of variance (ANOVA) technique and means were compared by using LSD at 5 percent $(0.05)$ probability level [19].

\section{Results and Discussion}

Fruits and oil from cultivated olive trees were broadly used in diet and drugs. The information about chemical constituents with medicinal possessions has been conformed from the widely available fruits, leaves, and oil of $O$. europaea. It has been revealed through the investigation that the wellbeing effects of olive oil such as postponement of aging must be credited to all its metabolite constituents and not to a single compound. They act through the decrease of the risk factor important to high blood pressure, numerous types of cancer, to the alteration of immunity and inflammatory [20]. Leaves of olive have been used for the treatment of wounds, fever, diabetes, gout, arterioscleroses, and hypertension since ancient times [21]. Olive leaf extract has conferred as useful for lowering blood pressure in humans [22] but recently, it has been revealed that leaf extracts of $O$. europaea have the predictable antimicrobial activity [23]. The studies about the therapeutic potential, quality of oil, metabolite constituent and antimicrobial potential of $O$. cuspidata (wild olive) was ignored all over the world because it has fruit of small size, contain small quantity of extractable oil and samples are difficult to collect from their original habitat often inaccessible or remote.

The antifungal activity of $O$. europaea L. leaves, seeds and $O$. cuspidata Wall. leaves, roots bark, stem bark and seeds were evaluated by well diffusion method against Aspergillus flavus, Alternaria alternata, Fusarium moniliform, Mauginiella scaettae, Trichothecium roseum, Magnaporthe grisea, Botrytis cinerea and yeast i.e. saccharomyces cerevisiae.

The antifungal potential of organic solvent extracts of investigated parts of $O$. europaea and $O$. cuspidata were tabulated in tables and also graphical representations of results shown in figures. The methanol extracts of O. europaea leaves and leaves, roots barks, stem bark and seeds of $O$. cuspidata were exhibiting some activity against Mauginiella scaettae $(8.7 \mathrm{~mm})$ and Magnaporthe grisea (14.3 mm), while all other fungi i.e. Aspergillus flavus, Alternaria alternata, Fusarium moniliform, Trichothecium roseum, Saccharomyces cerevisiae and Botrytis cinerea were resistant to this extract (Table. 1 and Fig. 1E).

The antifungal properties of $O$. cuspidata leaves were shown in Table, 3.11 and graphical presentation of results was recorded in Figure 3.6E. The methanol extract of $O$. cuspidata leaves revealed significant activity against Alternaria alternata $(10.70 \mathrm{~mm})$, Mauginiella scaettae (24.70 mm) and Magnaporthe grisea (27.70 $\mathrm{mm}$ ) while no activity was observed against other strains of fungi tested. The methanol extract of roots bark was also proven to be effective only against Magnaporthe grisea $(18.30 \mathrm{~mm})$ while all other fungi were resistant to this extract (Table 1, Fig 1A). The antifungal prospective of methanolic extract of stem bark of $O$. cuspidata 
exhibited affective against Magnaporthe grisea $(16.30 \mathrm{~mm})$ whereas all other fungi verified were unaffected by the extract (Table 1, Fig.1A).

The ethylacetate crude extracts of $O$. europaea leaves, seeds and $O$. cuspidata leaves, roots bark, stem barks and seeds were also tested against fungi which conferred variable results against these pathogens. The $O$. europaea leaves revealed some activity with zones of inhibition, 14.30 $\mathrm{mm}$ and $11.30 \mathrm{~mm}$ against Fusarium moniliform and Magnaporthe grisea whereas $O$. cuspidata leaves showed zones of inhibition against Alternaria alternata $(11.30 \mathrm{~mm})$, Mauginiella scaettae $(9.3 \mathrm{~mm})$ and Magnaporthe grisea (14.0 $\mathrm{mm})$. The $O$. europaea seeds extracts was observed affective against Aspergillus flavus (10.0 $\mathrm{mm})$, Alternaria alternata $(20.7 \mathrm{~mm})$, Mauginiella scaettae $(19.70 \mathrm{~mm})$, Trichothecium roseum (15.7 $\mathrm{mm})$, Magnaporthe grisea $(25.7 \mathrm{~mm})$ and Botrytis cinerea $(19.30 \mathrm{~mm})$ whereas $O$. cuspidata seeds exhibited potential against Aspergillus flavus $(15.7 \mathrm{~mm}), \quad$ Alternaria alternata (24.3 mm), Fusarium moniliform (24.3 $\mathrm{mm})$ Mauginiella scaettae $(30.7 \mathrm{~mm})$, Trichothecium roseum $(19.3 \mathrm{~mm})$, Saccharomyces cerevisiae $(15 \mathrm{~mm})$, Magnaporthe grisea $(35.7 \mathrm{~mm})$ and Botrytis cinerea $(25.3 \mathrm{~mm})$. The ethylacetate crude extracts of $O$. cuspidata leaves and seeds were proved to be highly effective against these pathogens as compared to $O$. europaea extracts of the same parts which revealing less activity only against some fungal strains (Table 1, Fig.1B). The antifungal activity of ethylacetate extracts of roots bark and stem barks of $O$. cuspidata were exposed with mean zones of inhibition against Magnaporthe grisea i.e. $17.7 \mathrm{~mm}$ and 14 $\mathrm{mm}$ respectively. Stem bark extract also showed activity against Mauginiella scaettae $(10.7 \mathrm{~mm})$.
The acetone crude extracts of $O$. europaea leaves, seeds and $O$. cuspidata leaves, roots bark, stem barks and seeds were also verified against fungi which were active against some strains. The $O$. europaea leaves revealed some activity with zones of inhibition, $11.30 \mathrm{~mm}$ against Magnaporthe grisea whereas $O$. cuspidata leaves showed zones of inhibition against Alternaria alternata $(10 \mathrm{~mm})$ and Magnaporthe grisea (17.7 mm). The O. europaea seeds extracts was observed inactive against all pathogens tested whereas $O$. cuspidata seeds exhibited potential against Aspergillus flavus (12.7 $\mathrm{mm})$, Alternaria alternata (15.7 $\mathrm{mm})$, Mauginiella scaettae $(14.3 \mathrm{~mm})$, Saccharomyces cerevisiae $(10.3 \mathrm{~mm})$, Magnaporthe grisea $(13.3 \mathrm{~mm})$ (Table 1, Fig.1C). These results are comparable with results of nystatin used as control except Mauginiella scaettae and Magnaporthe grisea which were resistant to this antibiotic but susceptible to the cure extracts used.

There is an incessant and crucial requirement to discover novel bioactive component particularly from plant sources with diverse chemical structures and new mechanisms of action to combat with infectious ailments. Additionally, the expansion of synthetic antimicrobials resistance in current healing procedure is a world concern [24]. Medicinal plants encompass a substantial number of different bioactive constituents. It has been demonstrated that bioactive components isolated from plants are very effective against microorganisms specifically human and plant pathogens $[25,26]$.

Most of the wild floras of Azad Jammu and Kashmir are rich in medicinal and aromatic properties. They are important sources of bioactive molecules, with application for the production of medicines and cosmetics [27]. In this study, the olives parts extracted with ethylacetate and methanol as compared to other solvents extracts proved to be 
significantly effectual against the fungal strains tested. Ethylacetate extracts exhibiting potential against pathogenic fungi. The $O$. cuspidata parts exhibited more antifungal potential against tested pathogens. This is because the polar solvent as compare to other solvents, may allows extracting all the phenolic compounds from the olives [28]. The current results revealed that the activity is mostly engrossed with ethylacetate and methanol extracts, indicating that the possible antifungal compounds were in the polar extracts. It is also evident that higher plants comprehend methanol soluble chemicals with substantial antimicrobial potential [29]. The polar solvents extracts conferred more potential activity against pathogenic microorganisms [30]. Buwa and Staden [31] concluded that the ethylacetate extracts were more effective against fungi compared with methanol extracts.

Traditional healers usually used water as solvent to prepare plant extracts. Though, in present study it was found that ethylacetate and methanol extracts exhibit more reliable antifungal activity and this assumption is also shared by other investigators [32].

Olive leaves may be useful in situations where lengthy usage of synthetic antibiotics inspire growth of opportunistic contagions [33], being especially effective against Staphylococcus, Bacillus, Klebsiella and Pseudomonas, four genera of bacteria which posture a chief resistance problem [34]. The antifungal properties of $O$. cuspidata leaves, stem and root barks extracts were tested for the first time in present work subsequently previous studies available in literature were focused exclusively on $O$. europaea fruits and leaves [35-37]. The ethylacetate and methanol extracts investigated in present study conferred a strong activity against disastrous pathogenic fungal strain (Table 1). O. cuspidata parts extracts prove to be good with antifungal potential while the nystatin an antifungal commercially available medicine was inactive against these pathogens (Fig.1 A-E). The information presented in literature concerning antimicrobial potential of phenolic compounds particularly obtained from cultivated olive seeds, predominantly oleuropein and hydroxytyrosol [38, 39]. Investigations of Markin et al. [10] and Pereira et al. [23] about antimicrobial activity of $O$. europaea leaves revealed the higher minimum inhibitory concentrations for the inhibition of fungal growth than the present investigation. In the present study methanolic extracts of leaves, seeds of cultivated olive and seeds, leaves, roots bark but not stem bark exhibited potent antifungal activity. Further, extracts from wild olive appeared to be particularly potent. The solid phase and HPLC fractions of Olea cuspidata leaves particularly 100 water, 5 and 100 percent methanol fractions exhibited potential antifungal activity against Magnaporthe grisea (Fig. 2, 3). According to Regasini et al. [40] and Helmerhorst et al. [41], the deaths from opportunistic fungal diseases is above fifty percent and only narrow spectrum antifungal medicines are available, therefore it is a need to isolate new antifungal drugs. On the bases of present investigation it is clear that olive species are best source for the antifungal medicines as they exhibiting excellent inhibitory against human as well as crop pathogens tested particularly wild olive. These results are in agreement with the previous studies [42, 43]. Moreover, in current study different extracts of wild and cultivated olives parts were investigated for their potential against eight fungi, which are known to cause reduction in the yield and quality of crops. As all other fungi, they are extremely responsive to environmental pressures and exhibit a capacity to adapt and 
Table 1. Antifungal activities of different extracts of $O$. cuspidata and $O$. europaea

\begin{tabular}{|c|c|c|c|c|c|c|c|c|c|c|c|}
\hline \multirow[t]{2}{*}{ S.No. } & \multirow{2}{*}{$\begin{array}{c}\text { Name of } \\
\text { Plant }\end{array}$} & \multirow{2}{*}{$\begin{array}{l}\text { Part } \\
\text { Used }\end{array}$} & \multirow[t]{2}{*}{ Solvent } & \multicolumn{8}{|c|}{ Mean Zone of Inhibition $(\mathrm{mm}) \pm$ Standard Error Mean $(\mathrm{SEM})$} \\
\hline & & & & Asperg & Altern & Fusari & Maugi & Tricho & Sacch & Magna & Botry \\
\hline 1 & O. europea & $\mathrm{L}$ & Ethyl acetate & $0.0 \pm 0.00$ & $0.0 \pm 0.00$ & 14. $3 \pm 0.33$ & $0.0 \pm 0.00$ & $0.0 \pm 0.00$ & $0.0 \pm 0.00$ & $11.3 \pm 0.33$ & $0.0 \pm 0.00$ \\
\hline 2 & O. europea & $\mathrm{L}$ & Acetone & $0.0 \pm 0.00$ & $0.0 \pm 0.00$ & $0.0 \pm 0.00$ & $0.0 \pm 0.00$ & $0.0 \pm 0.00$ & $0.0 \pm 0.00$ & $11.3 \pm 0.33$ & $0.0 \pm 0.00$ \\
\hline 3 & O. europea & $\mathrm{L}$ & Chloroform & $0.0 \pm 0.00$ & $0.0 \pm 0.00$ & $0.0 \pm 0.00$ & $0.0 \pm 0.00$ & $0.0 \pm 0.00$ & $0.0 \pm 0.00$ & $0.0 \pm 0.00$ & $0.0 \pm 0.00$ \\
\hline 4 & O. europea & $\mathrm{L}$ & Methanol & $0.0 \pm 0.00$ & $0.0 \pm 0.00$ & $0.0 \pm 0.00$ & $8.7 \pm 0.3$ & $0.0 \pm 0.00$ & $0.0 \pm 0.00$ & $14.3 \pm 0.33$ & $0.0 \pm 0.00$ \\
\hline 5 & O. europea & $\mathrm{S}$ & Ethyl acetate & $10.0 \pm 0.00$ & $20.7 \pm 0.3$ & $0.0 \pm 0.00$ & $19.7 \pm 0.33$ & $15.7 \pm 0.3$ & $0.0 \pm 0.00$ & $25.7 \pm 0.33$ & $19.3 \pm 0.33$ \\
\hline 6 & O. europea & $\mathrm{S}$ & Acetone & $0.0 \pm 0.00$ & $0.0 \pm 0.00$ & $0.0 \pm 0.00$ & $0.0 \pm 0.00$ & $0.0 \pm 0.00$ & $0.0 \pm 0.00$ & $0.0 \pm 0.00$ & $0.0 \pm 0.00$ \\
\hline 7 & O. europea & $\mathrm{S}$ & Chloroform & $0.0 \pm 0.00$ & $0.0 \pm 0.00$ & $0.0 \pm 0.00$ & $0.0 \pm 0.00$ & $0.0 \pm 0.00$ & $0.0 \pm 0.00$ & $0.0 \pm 0.00$ & $0.0 \pm 0.00$ \\
\hline 8 & O. europea & $\mathrm{S}$ & Methanol & $0.0 \pm 0.00$ & $0.0 \pm 0.00$ & $0.0 \pm 0.00$ & $10.3 \pm 0.33$ & $0.0 \pm 0.00$ & $0.0 \pm 0.00$ & $0.0 \pm 0.00$ & $11.3 \pm 0.3$ \\
\hline 9 & O. cuspidata & $\mathrm{L}$ & Ethyl acetate & $0.0 \pm 0.00$ & $11.3 \pm 0.33$ & $0.0 \pm 0.00$ & $9.3 \pm 0.3$ & $0.0 \pm 0.00$ & $0.0 \pm 0.00$ & $14.0 \pm 0.6$ & $0.0 \pm 0.00$ \\
\hline 10 & O. cuspidata & $\mathrm{L}$ & Acetone & $0.0 \pm 0.00$ & $10.0 \pm 0.3$ & $0.0 \pm 0.00$ & $0.0 \pm 0.00$ & $0.0 \pm 0.00$ & $0.0 \pm 0.00$ & $17.7 \pm 0.3$ & $0.0 \pm 0.00$ \\
\hline 11 & O. cuspidata & $\mathrm{L}$ & Chloroform & $0.0 \pm 0.00$ & $0.0 \pm 0.00$ & $0.0 \pm 0.00$ & $0.0 \pm 0.00$ & $0.0 \pm 0.00$ & $0.0 \pm 0.00$ & $0.0 \pm 0.00$ & $0.0 \pm 0.00$ \\
\hline 12 & O. cuspidata & $\mathrm{L}$ & Methanol & $0.0 \pm 0.00$ & $10.7 \pm 0.33$ & $0.0 \pm 0.00$ & $24.7 \pm 0.33$ & $0.0 \pm 0.00$ & $0.0 \pm 0.00$ & $27.7 \pm 0.33$ & $0.0 \pm 0.00$ \\
\hline 13 & O. cuspidata & $\mathrm{S}$ & Ethyl acetate & $15.7 \pm 0.33$ & $24.3 \pm 0.3$ & $24.3 \pm 0.33$ & $30.7 \pm 0.33$ & $19.3 \pm 0.3$ & $15.0 \pm 0.6$ & $35.7 \pm 0.3$ & $25.3 \pm 0.33$ \\
\hline 14 & O. cuspidata & $\mathrm{S}$ & Acetone & $12.7 \pm 0.3$ & $15.7 \pm 0.33$ & $0.0 \pm 0.00$ & $14.3 \pm 0.3$ & $0.0 \pm 0.00$ & $10.3 \pm 0.33$ & $13.3 \pm 0.33$ & $0.0 \pm 0.00$ \\
\hline 15 & O. cuspidata & $\mathrm{S}$ & Chloroform & $0.0 \pm 0.00$ & $0.0 \pm 0.00$ & $0.0 \pm 0.00$ & $0.0 \pm 0.00$ & $0.0 \pm 0.00$ & $0.0 \pm 0.00$ & $0.0 \pm 0.00$ & $0.0 \pm 0.00$ \\
\hline 16 & O. cuspidata & $\mathrm{S}$ & Methanol & $0.0 \pm 0.00$ & $9.3 \pm 0.33$ & $0.0 \pm 0.00$ & $11.3 \pm 0.33$ & $0.0 \pm 0.00$ & $10.7 \pm 0.3$ & $19.7 \pm 0.3$ & $0.0 \pm 0.00$ \\
\hline 17 & O. cuspidata & SB & Ethyl acetate & $0.0 \pm 0.00$ & & $0.0 \pm 0.00$ & & $0.0 \pm 0.00$ & $0.0 \pm 0.00$ & $17.7 \pm 0.3$ & $0.0 \pm 0.00$ \\
\hline 18 & O. cuspidata & SB & Acetone & $0.0 \pm 0.00$ & $0.0 \pm 0.00$ & $0.0 \pm 0.00$ & $0.0 \pm 0.00$ & $0.0 \pm 0.00$ & $0.0 \pm 0.00$ & $18.0 \pm 0.00$ & $0.0 \pm 0.00$ \\
\hline 19 & O. cuspidata & SB & Chloroform & $0.0 \pm 0.00$ & $0.0 \pm 0.00$ & $0.0 \pm 0.00$ & $0.0 \pm 0.00$ & $0.0 \pm 0.00$ & $0.0 \pm 0.00$ & $0.0 \pm 0.00$ & $0.0 \pm 0.00$ \\
\hline 20 & O. cuspidata & SB & Methanol & $0.0 \pm 0.00$ & $0.0 \pm 0.00$ & $0.0 \pm 0.00$ & $0.0 \pm 0.00$ & $0.0 \pm 0.00$ & $0.0 \pm 0.00$ & $16.0 \pm 0.3$ & $0.0 \pm 0.00$ \\
\hline 21 & O. cuspidata & $\mathrm{RB}$ & Ethyl acetate & $0.0 \pm 0.00$ & $0.0 \pm 0.00$ & $0.0 \pm 0.00$ & $0.0 \pm 0.00$ & $0.0 \pm 0.00$ & $0.0 \pm 0.00$ & $14.0 \pm 0.33$ & $0.0 \pm 0.00$ \\
\hline 22 & O. cuspidata & $\mathrm{RB}$ & Acetone & $0.0 \pm 0.00$ & $0.0 \pm 0.00$ & $0.0 \pm 0.00$ & $0.0 \pm 0.00$ & $0.0 \pm 0.00$ & $0.0 \pm 0.00$ & $19.7 \pm 0.3$ & $0.0 \pm 0.00$ \\
\hline 23 & O. cuspidata & $\mathrm{RB}$ & Chloroform & $0.0 \pm 0.00$ & $0.0 \pm 0.00$ & $0.0 \pm 0.00$ & $0.0 \pm 0.00$ & $0.0 \pm 0.00$ & $0.0 \pm 0.00$ & $0.0 \pm 0.00$ & $0.0 \pm 0.00$ \\
\hline 24 & O. cuspidata & $\mathrm{RB}$ & Methanol & $0.0 \pm 0.00$ & $0.0 \pm 0.00$ & $0.0 \pm 0.00$ & $0.0 \pm 0.00$ & $0.0 \pm 0.00$ & $0.0 \pm 0.00$ & $18.3 \pm 0.33$ & $0.0 \pm 0.00$ \\
\hline 25 & Nystatin & & $00 \mathrm{U} / 10 \mu \mathrm{l}$ & $30.7 \pm 0.3$ & $30.0 \pm 0.00$ & $30.0 \pm 0.00$ & $0.00 \pm 0.00$ & $20.0 \pm 0.00$ & $30.7 \pm 0.3$ & $0.0 \pm 0.00$ & $35.3 \pm 0.33$ \\
\hline
\end{tabular}

Key: Asperg = Aspergillus flavus, Altern = Alternaria alternata, Fusari $=$ Fusarium moniliform, Maugi = Mauginiella scaettae, Tricho $=$ Trichothecium roseum, Sacch = Saccharomyces cerevisiae, Magna = Magnaporthe grisea, Botry = Botrytis cinerea $\mathbf{L}=$ Leaves $\quad \mathbf{S}=$ Seeds $\quad \mathbf{S B}=$ Stem Bark $\quad \mathbf{R B}=$ Roots Bark 

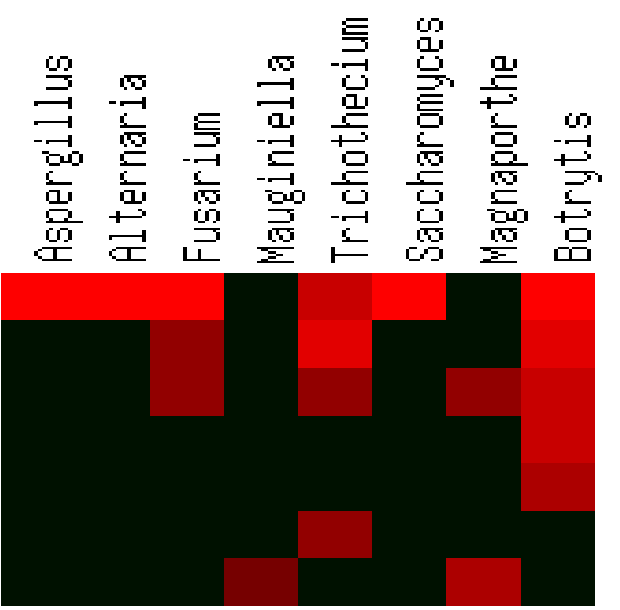

Nystatin

cuspidata_Leaves

cuspidata_Seeds

cuspidata_Root_Bark

cuspidata_Stem_Bark

eurapea_Seeds

eurapea_Leaves

Figure 1 (A): Antifungal activity of methanol extracts of all parts
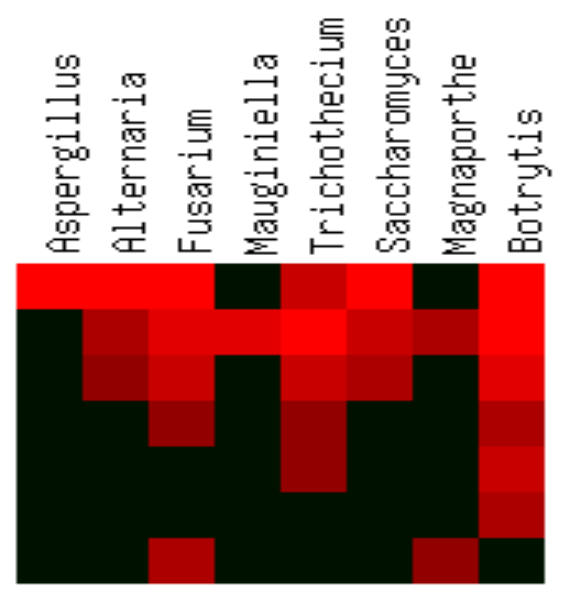

\section{Nystatin}

cuspidata_Seeds

eurapea_Seeds

cuspidata_Leaves

cuspidata_Stem_Bark

cuspidata_Root_Bark

eurapea_Leaves

Figure 1 (B): Antifungal activities of ethylacetate extracts of all parts

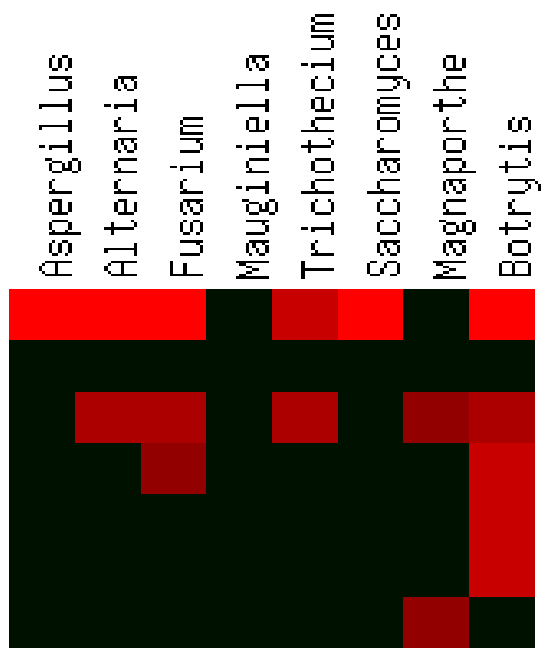

Nystatin

europea_Seeds

cuspidata_Seeds

cuspidata_Leaves

cuspidata_Root_Bark

cuspidata_Stem_Bark

europea_Leaves

Figure 1 (C): Antifungal activities of acetone extracts of all parts 


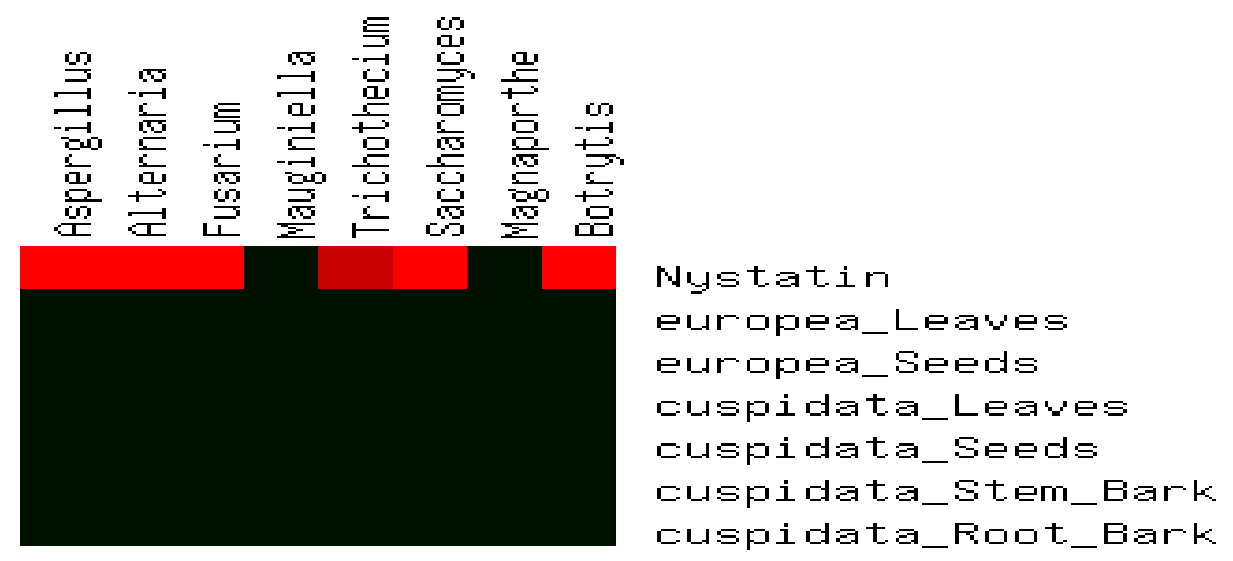

Figure 1 (D): Antifungal activities of chloroform extracts of all parts

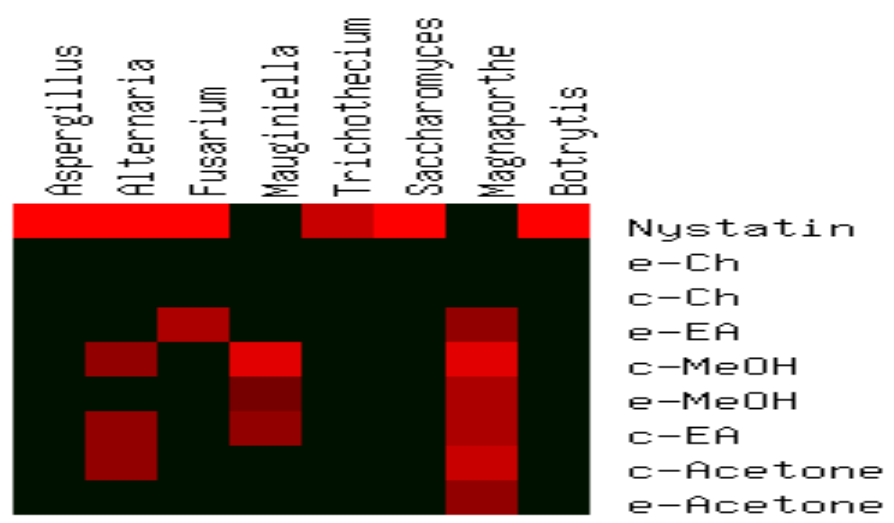

Figure 1 (E): Antifungal activities of leaves of $O$. europaea

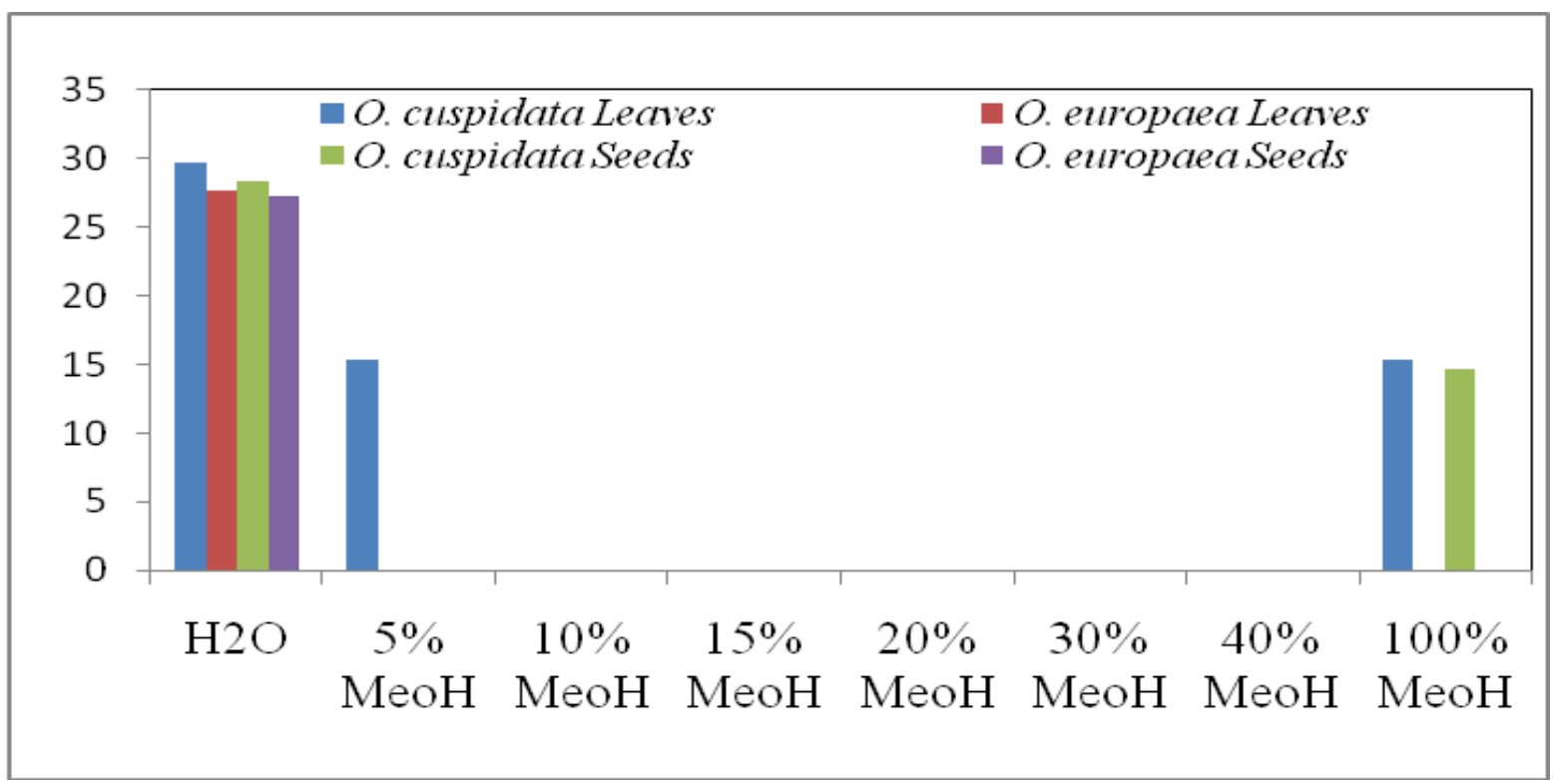

Figure-2. Effect of solid phase extracts against Magnaporthe grisea 


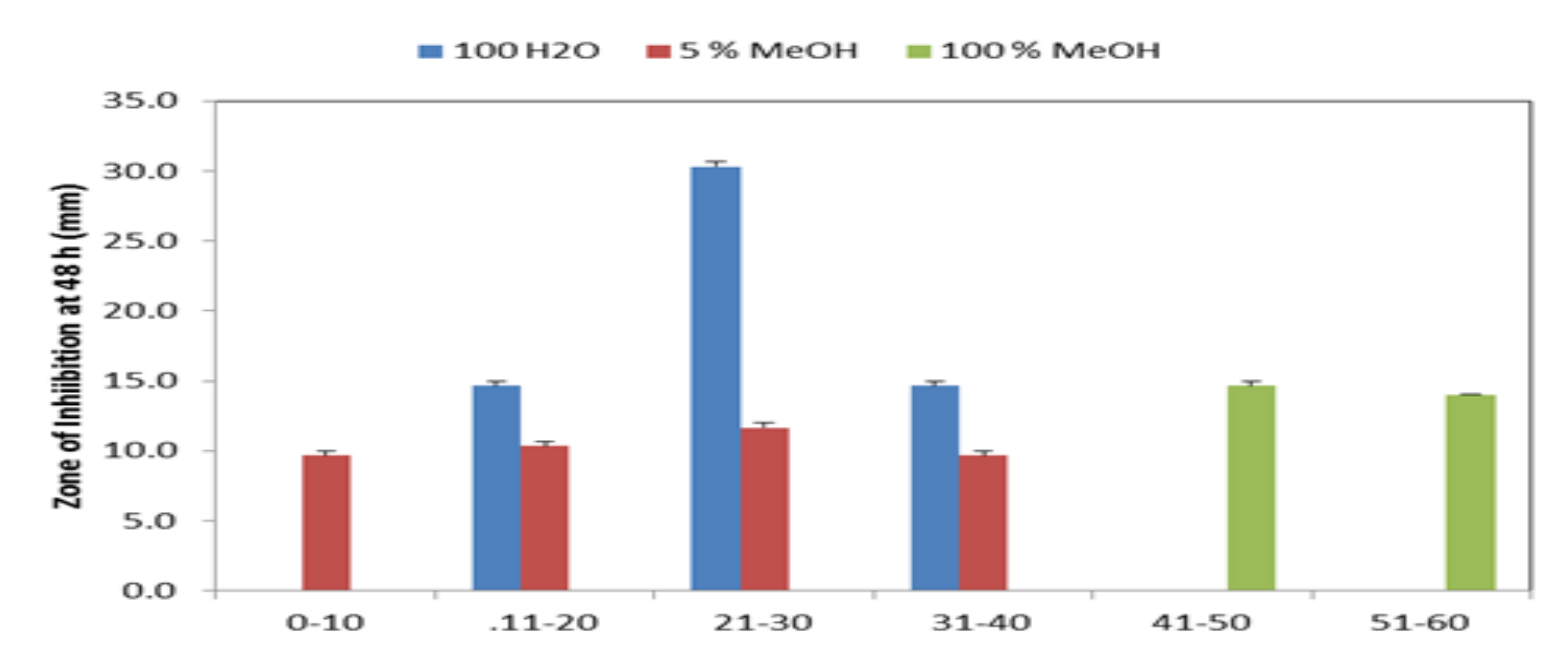

Figure-3. Effect of preparative HPLC fractions against Magnaporthe grisea

to colonize a variety of ecological niches. Alternaria alternata is an attendant to tomatoes, potatoes, paprika, Botrytis cinerea attacks grapes, berry-fruits, some vegetables too, while Fusarium culmorum causes a degradation of cereal grains. The latter is also known for its production of mycotoxine. Extracts of wild olive parts showed a potential antifungal activity against Aspergillus flavus, Alternaria alternata, Mauginiella scaettae, Saccharomyces cerevisiae and Magnaporthe grisea (Table 1, Fig.1 A-E).

In the present investigations the crude extracts, solid phase and HPLC fractions were used instead of individual phenolic compound due to reasons that the antimicrobial properties of phenolic components are recognized $[25,44]$ and extracts may be more advantageous as compare to single isolated chemical, since a bioactive single compound can alter its possessions in the presence of other constituents found in extracts [24]. The synergistic effects of phytochemicals in vegetables and fruits are responsible for their potent bioactive activities and the benefit of a diet rich in fruits and vegetables is attributed to the complex mixture of phytochemicals present in whole foods [45].
This explains why no individual antifungal can replace the mixture of natural phytochemicals to attain the health benefits.

The Olea cuspidata leaves proved to be highly effective against tested fungi as compared to Olea europaea. The wild olive extracts are efficiently inhibiting or delaying the growth rate of microorganisms. This study is in line with the previous study of Bisignano et al. [38]. Antifungal activities observed observed in current study are also in line with the former investigations that reported in literature [10, 33, 34].

\section{Conclusion}

On the bases of present investigation it is concluded that olive species are best source for the antifungal medicines as they exhibiting excellent inhibitory effect against human as well as crop pathogenic fungi tested. In the present study methanolic extracts of leaves, seeds of cultivated olive and seeds, leaves, roots bark but not stem bark exhibited substantial antifungal activity. Further, extracts from wild olive appeared to be particularly potent. This study demonstrate that the use of wild olive leaves extracts as medicines may reduce the risk of fungal infections, particularly in situations where lengthy usage of synthetic fungicidal inspire growth of opportunistic 
contagions. The use of extracts is suggested to achieve benefits due to the additive and synergistic effects of phytochemicals present in whole extract.

\section{References}

1. Benavente GO, Castillo J, Lorente J, Ortuno A \& Rio JAD (2000). Antioxidant activity of phenolics from Olea europaea L. leaves. Food Chem. 68:457-462.

2. Khayyal MT, El-Ghazaly MA, Abdallah DM, Nassar NN, Okpanyi SN \& Kreuter MH (2002). Blood pressure lowering effect of an olive leaf extract (Olea europaea) in L-NAME induced hypertension in rats. Arzneimittelforschung 52: 797-802.

3. Zarzuelo A (1991). Vasodilator effect of olive leaf. Planta Med, 57: 417-419.

4. Tuck KL \& Hayball PJ 2002. Major phenolic compounds in olive oil: metabolism and health effects. J Nutr. Biochem. 13: 636-644.

5. Korukluoglu M, Sahan Y, Yigit A, Tumay Ozer E \& Gucer S (2004). In vitro antibacterial activity of olive leaf (Olea europaea L.) extracts and their chemical characterization. KusadasIAydin, 4th Aegean Analytical Chemistry Days, Turkey.

6. Micol V, Caturla N, Pèrez-Fons L, Más V \& Pèrez EA (2005). The olive leaf extract exhibits antiviral activity against viral haemorhagic septicaemia rhabdovirus (VHSV). Antiviral Res. 66: 129-136.

7. Aziz NH, Farag SE, Mousa LA \& AboZaid MA (1998). Comparative antibacterial and antifungal effects of some phenolic compounds. Microbios, 93: 43-54.

8. Yigit A, Sahan Y \& Korukluoglu M (2001). Antimicrobial substances found in olive leaves and olive. 2nd International AltInoluk "Antandros"
Olive Busines Symposium, Turkey: 139147.

9. Gourama H \& Bullerman LB (1987). Effect of oleuropein on growth and aflatoxin production by Aspergillus parasiticus. Lebensm. Wiss. U. Technol. 20: 226-228.

10. Markin D, Duek L and Berdicevsky I (2003). In vitro antimicrobial activity of olive leaves. Mycoses, 46: 132-136.

11. Sousa A, Ferreira ICFR, Calhelha R, Andrade PB, Valentao P, Seabra R, Estevinho L, Bento A \& Pereira JA (2006). Phenolics and antimicrobial activity of traditional stoned table olives 'alcaparra'. Bioorg. Med. Chem. 14:8533-38.

12. Battinelli L, Daniele C, Cristiani G \& Mazzanti $G$ (2006). In vitro antifungal and anti-elastase activity of some aliphatic aldehydes from Olea europaea L. fruit. Phytomedicine 13:558-563.

13. Evans DG, Everis K \& Betts GD (2004). Use of survival analysis and Classification and Regression Trees to model the growth/no growth boundary of spoilage yeasts as affected by alcohol, $\mathrm{pH}$, sucrose, sorbate and temperature. Int. J. Food Microbiol. 92:55-67.

14. Ismail SAS, Deaka T, Abd El-Rahman HA, Yassien MAM \& Beuchat LR (2000). Presence and changes in populations of yeasts on raw and processed poultry products stored at refrigeration temperature. Int. J. Food Microbiol. 62: 113-121.

15. Rawlins EA \& Tindall B (1977). Bently's Text Book of pharmaceutics $8^{\text {th }}$ edition. : 174-198.

16. Pelczar M \& Reid RD (1965). Microbiology (second ed), McGraw-Hill, New York.

17. Perez C, Paul M \& Bezique P (1990). An Antibiotic assay by the agar well 
diffusion method. Alta Biom. Group Exper. 15:109-113.

18. Salle AJ (1973). Laboratory Manual on Fundamental Principles of Bacteriology. McGraw-Hill Book Company, New York, USA. : 201.

19. Steel RGD \& Torrie JH (1980). Principles and Procedures of Statistics. Mc Graw Hill Book Co. Inc. New York. : 134-145.

20. Colomer R, Nogueira JMM, Luna PPG, Peris PG, Garcia AL, Zarazaga A, Quecedo L, del Llano J, Usan L \& Casimiro C (2007). Fatty acids, cancer and cachexia: a systematic review of the literature. Br J Nutr. 97:823-831.

21. Janicke C, Grunwald J \& Brendler T (2008). Food supplementation with an olive (Olea europaea L.) leaf extract reduces blood pressure in borderline hypertensive monozygotic twins. Phyto. Res. 22:1239-1242.

22. Perrinjaquet MT, Busjahn A, Schmidlin C, Schmidt A, Bradl B \& Aydogan C (2008). Food supplementation with an olive (Olea europaea L.) leaf extract reduces blood pressure in borderline hypertensive monozygotic twins. Phytother. Res. 22:1239-1242.

23. Pereira AP, Ferreira ICFR, Marcelino F, Valenta P, Andrade PB, Seabra R, Estevinho L, Bento A \& Pereira JA (2007). Phenolic compounds and antimicrobial activity of olive (Olea europaea L.) leaves. Molecules, 12:1153-1162.

24. Borchers AT, Keen CL \& Gerstiwin ME (2004). Mushrooms, tumors, and immunity: an update. Exp. Biol. Med. 229:393-406.

25. Pereira JA, Pereira AP, Ferreira ICFR, Valentao P, Andrade PB, Seabra R, Estevinho L \& Bento A (2006). Table olives from Portugal: phenolic compounds, antioxidant potential and antimicrobial activity. J Agri. Food Chem. 54: 8425-8431.

26. Puupponen PR, Nohynek L, Meier C, Kahkonen M, Heinonen M, Hopia A \& Oksman CKM (2001). Antimicrobial properties of phenolic compounds from berries. J App. Microb. 90: 494-507.

27. Heinrich M \& Gibbons S (2001). Ethonopharmacology in drug discovery: an analysis of its role and potential countribution. J Phar. Pharm. 53: 425432.

28. Pareke J \& Chanda S (2007). In vitro screening of antibacterial activity of aqueous and alcoholic extracts of various Indian plant species against selected pathogens from Enterobacteriaceae. A J M R., 1:92-99.

29. Mohan S, Abdul AB, Wahab SIA, AlZubairi AS \& Elhassan MM (2008). Antibacterial and antioxidant activities of Typhonium flagelliforme (Lodd.) Blume tuber. A J Bioch. Biot. 4: 402-407.

30. Mahasneh A \& El-Oqlah A (1999). Antimicrobial activity of extracts of herbal plants used in the traditional medicine in Jordan. J Ethnoph., 64: 271276.

31. Buwa LV \& Staden JV (2006). Antibacterial and antifungal activity of traditional medicinal plants used against venereal diseases in South Africa. J Ethnoph. 103: 139-142.

32. Aliero AA \& Afolayan AJ (2006). Antimicrobial activity of Solanum tomentosum. A J Biot. 5:369-372.

33. Verduyn LFM, Meis JF \& Voss A (1999). Nosocomial fungal infections: candidaemia. Diagn. Microb. Infect. Dis. 34: 213-220.

34. Neu HC (1992). The crisis in antibiotic resistance. Science, 257:1064-1073. 
35. Gordon MH, Martins FP \& Almeida M (2001). Antioxidant activity of hydroxytyrosol acetate compared with that of other olive oil polyphenols. J Agri. Food Chem. 49:2480-2485.

36. Paiva MF, Gordon $\mathrm{MH} \&$ Gameiro $\mathrm{P}$ (2003). Activity and location of olive oil phenolic antioxidants in liposomes. Chem. Phys. Lipids. 124:23-36.

37. Meirinhos J, Silva B, Valentao P, Seabra RM, Pereira JA, Dias A, Andrade PB \& Ferreres F (2005). Analysis and quantification of flavonoidic compounds from Portuguese olive (Oleae europeae L.) leaf cultivars. Nat. Prod. Res. 19:189195.

38. Bisignano $\mathrm{G}$, Tomaino A, Lo Cascio R, Crisafi G, Uccella N \& Saija A (1999). On the in-vitro activity of oleuropein and hydroxytyrosol. J Pharm. Pharmacol. 51:971-974.

39. Soni MG, Burdock GA, Christian MS, Bitler CM \& Crea R (2006). Safety assessment of aqueous olive pulp extract as an antioxidant or antimicrobial agent in foods. Food Chem. Toxicol. 44:903915.

40. Regasini LO, Cotinguiba F, Morandim AA, Kato MJ, Scorzoni L, Gianni MJM, Bolzani VS \& Furian M (2009). Antimicrobial activity of Piper arboretum and Piper tuberculatum
(Piperaceae) against opportunistic yeasts. A J Biot. 8: 2866-2870.

41. Helmerhorst EJ, Reijnders IM, Hof WVT, Smith IS, Veerman ECJ \& Amerongen AVN 1999. Amphotericin B and fluconazole-resistant Candida spp, Aspergillus fumigatus and other newly emerging pathogenic fungi are susceptible to basic antifungal peptides. Amicrob. Agents. Chem. 43:702-704.

42. Masoko P, Mmushi TJ, Mogashoa MM, Mokgotho MP, Mampuru LJ \& Howard RL (2008). In vitro evaluation of the antifungal activity of Sclerocarya birrea extracts against pathogenic yeast. A J Biot. 7: 3521-3526.

43. Adegoke AA \& Tayo BCA (2009). Antimicrobial activity and phytochemical analysis of leaf extracts of Lasienthera africanum. A. J. Biot., 6: 77-80.

44. Proestos C, Chorianopoulos N, Nychas GJE \& Komaitis M (2005). RP-HPLC analysis of the phenolic compounds of plant extracts. Investigation of their antioxidant capacity and antimicrobial activity. J. Agric. Food Chem., 53:11901195.

45. Liu RH (2003). Health benefits of fruits and vegetables are from additive and synergistic combination of phytochemicals. A J Clin. Nutr. 78:517520. 